\title{
PERANCANGAN APLIKASI SIMPAN PINJAM PADA KOPERASI KARYAWAN '71' PT. NIKOMAS GEMILANG BERBASIS ANDROID
}

\author{
Waliadi Gunawan $^{1}$, Nur Hidayanti ${ }^{2}$, Rudianto ${ }^{3}$, Fikri Al Hakim ${ }^{4}$ \\ 1,2,3,4 Jurusan Teknik Informatika Fakultas Ilmu Kompter Universitas Banten Jaya \\ Jln. Ciwaru Raya No. 73 - Kota Serang
}

\author{
${ }^{1}$ waliadigunawan@unbaja.ac.id \\ ${ }^{2}$ nurhidayanti@unbaja.ac.id \\ ${ }^{3}$ rudianto@unbaja.ac.id \\ 4fikrialhakim38@gmail.com
}

\begin{abstract}
Abstrak
71' Koperasi Karyawan PT. Nikiomas Gemilang merupakan salah satu lembaga keuangan non bank di dalam perusahaan yang berfungsi memberikan pelayanan berupa pinjaman dan tempat menyimpan uang bagi para anggotanya. Misi Koperasi karyawan '71' PT. Nikomas Gemilang yaitu memberikan pelayanan terbaik seperti memberikan pinjaman secara angsuran yang dibayarkan kepada karyawan PT. Nikomas Gemilang yang merupakan anggota dari karyawan Koperasi '71' PT. Nikomas Gemilang. Sistem Informasi Pengolahan Data PT. Nikomas Gemilang masih terdapat beberapa kekurangan yang berdampak pada keterlambatan proses pembayaran baik simpanan maupun cicilan. Tujuan dari penelitian ini adalah untuk menciptakan kesejahteraan bagi karyawan PT. Nikomas Gemilang. Untuk mewujudkan hal tersebut diperlukan suatu metode perancangan sistem, dan dikembangkan metode waterfall dengan menggunakan Unified Modeling Language (UML) untuk pemodelan sistem visual, sedangkan pemrograman yang digunakan menggunakan bahasa dart dengan framework flutter dan database Mysql. Berdasarkan hal tersebut maka peneliti akan membuat sebuah aplikasi simpan pinjam berbasis android dengan judul "Desain Aplikasi Simpan Pinjam Koperasi Pegawai‘ 71" PT. Nikomas Gemilang Berbasis Android".
\end{abstract}

Kata Kunci: Karyawan, Perancangan, Aplikasi, Simpan Pinjam, UML

\section{PENDAHULUAN}

Koperasi merupakan suatu perkumpulan yang didirikan oleh sekelompok orang atau badan hukum koperasi yang memiliki keterbatasan kemampuan ekonomi, bertujuan untuk memperjuangkan peningkatan kesejahteraan anggotanya. Koperasi memegang peranan penting dalam pertumbuhan ekonomi masyarakat seperti harga bahan pokok yang tergolong murah dan juga ada koperasi yang menawarkan peminjaman dan penyimpanan uang untuk masyarakat [1]. Koperasi adalah badan usaha yang beranggotakan orang seorang atau badan hukum koperasi dengan melandaskan kegiatannya berdasarkan prinsip koperasi sekaligus sebagai gerakan ekonomi rakyat yang berdasar atas asas kekeluargaan [2]. Prinsip- prinsip koperasi merupakan landasan pokok koperasi dalam menjalankan usahanya sebagai badan usaha dan gerakan ekonomi rakyat, koperasi merupakan organisasi bisnis yang dimiliki dan dioperasikan oleh orang-seorang demi kepentingan bersama [3]. Simpan pinjam merupakan suatu transaksi yang menghimpun dana dalam bentuk pinjaman dan menyalurkannya kembali dalam bentuk pinjaman kepada anggota yang membutuhkannya [4]. Tujuan diadakannya penelitian ini yaitu, Untuk mengetahui apilkasi simpan pinjam yang sedang berjalan pada Koperasi Karyawan '71' PT. Nikomas Gemilang, untuk merancang apilkasi simpan pinjam, untuk melakukan pengujian terhadap aplikasi simapan pinjam, untuk mengimplementasikan aplikasi simpan pinjam berbasis android.

Berdasarkan paparan diatas peneliti menyimpulkan bahwa koperasi adalah suatu organisasi atau badan usaha yang bertujuan untuk mensejahterakan anggotanya [5]. Dengan sistem aplikasi berbasis android nasabah tidak perlu menunggu karyawan koperasi datang berkunjung untuk melakukan pembayaran angsuran, di mana nasabah dapat secara langsung memasukkan kode transfer dan 
nominal angsuran untuk melaporkan pembayaran angsuran, nasabah juga dapat melihat history pembayaran angsuran yang diajukan di mana menunggu proses persetujuan dari admin, dan jika sudah disetujui oleh admin, maka nasabah juga dapat melihat history angsuran yang sudah dibayarkan dan mendapat persetujuan admin [6].

Android merupakan OS (Operating System) Mobile yang tumbuh ditengah OS lainnya yang berkembang dewasa ini [7]. OS lainnya seperti Windows Mobile, iPhone OS, Symbian, dan masih banyak lagi. Akan tetapi, OS yang ada ini berjalan dengan memprioritaskan aplikasi inti yang dibangun sendiri tanpa melihat potensi yang cukup besar dari aplikasi pihak ketiga. Oleh karena itu, adanya keterbatasan dari aplikasi pihak ketiga untuk mendapatkan data asli ponsel, berkomunikasi antar proses serta keterbatasan distribusi aplikasi pihak ketiga untuk platform mereka. Sesungguhnya tidak ada batasan yang tegas diantara berbagai konsep dan konstruksi dalam UML, tetapi untuk menyederhanakannya, kita membagi sejumlah besar konsep dan dalam UML menjadi beberapa view [8]. Suatu view sendiri pada dasarnya merupakan sejumlah konstruksi pemodelan UML yang merepresentasikan suatu aspek tertentu dari sistem atau perangkat lunak yang sedang kita kembangkan. Pada peringkat paling atas, viewview sesungguhnya dapat dibagi menjadi tiga area utama, yaitu: klasifikasi struktural (structural classification), perilaku dinamis (dinamic behaviour), serta pengolahan atau manajemen model (model management).

1) Jenis-jenis diagram UML (Unified Modeling Language) bahwa : Berikut ini adalah definisi mengenai 5 diagram UML :

a) Use Case Diagram secara grafis menggambarkan interaksi antara sistem, sistem eksternal dan pengguna. Dengan kata lain use case diagram secara grafis mendeskripsikan siapa yang akan menggunakan sistem dan dalam cara apa pengguna (user) mengharapkan interaksi dengan sistem itu. Use case secara naratif digunakan untuk secara tekstual menggambarkan sekuensi langkah-langkah dari setiap interaksi.

b) Class Diagram menggambarkan struktur object sistem. Diagram ini menunjukkan class object yang menyusun sistem dan juga hubungan antara class object tersebut.

c) Sequence Diagram secara grafis menggambarkan bagaimana object berinteraksi dengan satu sama lain melalui pesan pada sekuensi sebuah use case atau operasi.

d) State Chart Diagram digunakan untuk memodelkan behaviour object khusus yang dinamis. Diagram ini mengilustrasikan siklus hidup object berbagai keadaan yang dapat diasumsikan oleh object dan event-event (kejadian) yang menyebabkan objek beralih dari satu state ke state yang lain. e) Activity Diagram secara grafis digunakan untuk menggambarkan rangkaian aliran aktivitas baik proses bisnis maupun use case. Activity diagram dapat juga digunakan untuk memodelkan action yang akan dilakukan saat sebuah operasi dieksekusi, dan memodelkan hasil dari action tersebut.

\section{METODOLOGI PENELITIAN}

\section{Metode Pengumpulan Data}

a. Wawancara

Suatu penilitian yang dilakukan dengan cara mengumpulkan data melaluai tanya jawab atau konsultasi dengan staff koperasi yang berhubungan langsung dengan permasalahan yang dibahas untuk melengkapi data-data yang dibutuhkan.

b. Survey

Metode pegumpulan data dengan melihat, meneliti, mengamati secara langsung bagaimana proses pelayanan simpan pinjam yang dilakukan oleh petugas pada koperasi karyawan "71” PT. Nikomas Gemilang.

c. Studi Pustaka.

Metode pengumpulan data dengan mencari sumber informasi dari buku dan media referensi lainnya.

2. Metode Analisa Sistem

Metodologi ini perancangan sistem pengolahan data simpan pinjam yang digunakan adalah dengan metode Waterfall, yaitu dengan urutan prosedur sebagai berikut [9] :

a. Definisi Masalah, yaitu mendefinisikan permaslahan, penyebab dan srategi pemecahannya

b. Analisis, yaitu apa yang digunakan untuk memecahkan memecahkan masalah (batasan, data dan proses).

c. Desain, yaitu bagaimana masalah akan dipecahkan.

d. Devolopment, yaitu pembuatan program system pengolaha data simpan pinjam.

e. Testing yaitu masa percobaan setelah melalui proses testing.

f. Implementasi, yaitu penggunaan program setelah melalui proses testing.

g. Perbaikan, yaitu perbaikan akan dilakukan setiap kali ada pengembangan atau permasalahan yang muncul dikemudian hari.

\section{Analisa Sistem Berjalan}

Kegiatan analisa merupakan kegiatan penguraian suatu sistem informasi yang utuh dan nyata kedalam bagian-bagian atau komponen-komponen komputer dengan tujuan untuk mengidentifikasi serta mengevaluasi masalah-masalah yang muncul, kesempatan, hambatanhambatan yang mungkin terjadi dan kebutuhankebutuhan yang diharapkan sehingga menjadi baik dan sesuai dengan kebutuhan serta perkembangan teknologi. Dari hasil analisa yang dilakukan analis pada sistem yang berjalan pada Koperasi Karyawan "71" PT. Nikomas Gemilang terdapat permasalahan antara lain : 
1. Proses pencatatan/pengolahan data baik data keanggotaan baru maupun transakasi simpan pinjam serta pembelian produk oleh anggota dilakukan dengan cara mencatatkan setiap kegiatan transaksi kedalam buku oleh koperasi atau dilakukan dengan cara manual.

2. Pegawai koperasi mengarsipkan setiap transaksi yang telah dilakukan sebagai bukti.

3. Kerangkapan data dan kesalahan pengarsipan kerap terjadi pada proses pengarsipan.

\section{HASIL DAN PEMBAHASAN}

\section{Pembuatan Unified Modeling Language (UML)}

Dalam perancangan sistem aplikasi simpan pinjam pada Koperasi Karyawan 71 PT. Nikomas Gemilang berbasis android ini penulis menggunakan pemodelan Unified Modeling Language (UML).

\section{a. Use Case Digaram}

Berikut ini pemodelan Use Case diagram sistem aplikasi simpan pinjam pada Koperasi Karyawan 71 PT. Nikomas Gemilang berbasis android.

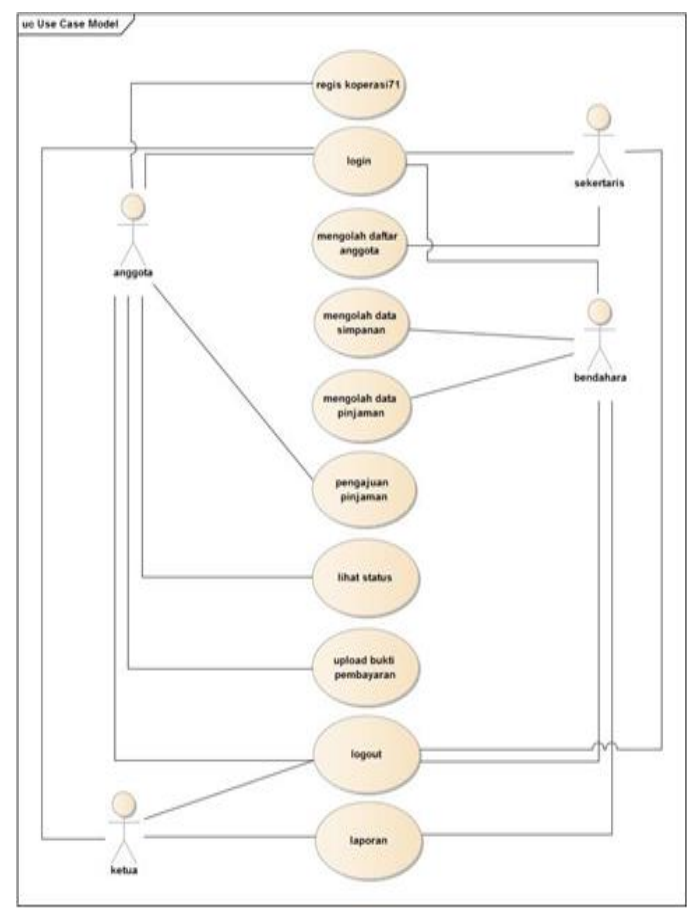

Gambar 1. Use Case Diagram

Tabel 1. Deskripsi Use Case Diagram

\begin{tabular}{ccl}
\hline No & \multicolumn{1}{c}{ Tools } & \multicolumn{1}{c}{ Deskripsi } \\
\hline 1 & Admin & $\begin{array}{l}\text { Pihak yang mengelola data } \\
\text { anggota koperasi }\end{array}$ \\
2 & Karyawan & $\begin{array}{l}\text { Pihak yang akan mendaftar } \\
\text { menjadi anggota }\end{array}$ \\
3 & Anggota & $\begin{array}{l}\text { Pihak yang bisa mengakses } \\
\text { menu-menu anggota }\end{array}$ \\
\hline
\end{tabular}

\begin{tabular}{|c|c|c|}
\hline 4 & Ketua & $\begin{array}{l}\text { Pihak yang menerima laporan } \\
\text { dari admin }\end{array}$ \\
\hline 5 & Pendaftaran & $\begin{array}{l}\text { Tahap awal bagi karyawan } \\
\text { yang akan mendaftar menjadi } \\
\text { anggota }\end{array}$ \\
\hline 6 & Login & $\begin{array}{l}\text { Tahap awal untuk kedua } \\
\text { users masuk sitem aplikasi } \\
\text { koperasi berbasis android }\end{array}$ \\
\hline 7 & $\begin{array}{l}\text { Mengolah data } \\
\text { daftar anggota }\end{array}$ & $\begin{array}{lcc}\text { Menu yang } & \text { hanya bisa } \\
\text { diakses oleh } & \text { admin } & \text { untuk } \\
\text { memperbarui } & \text { data } & \text { daftar } \\
\text { anggota } & & \end{array}$ \\
\hline 8 & $\begin{array}{l}\text { Mengolah } \\
\text { Simpanan }\end{array}$ & $\begin{array}{l}\text { Menu yang hanya bisa } \\
\text { diakses oleh admin untuk } \\
\text { memperbarui data simpanan } \\
\text { anggota }\end{array}$ \\
\hline 9 & $\begin{array}{l}\text { Mengolah } \\
\text { pinjaman }\end{array}$ & $\begin{array}{l}\text { Menu yang hanya bisa } \\
\text { diakses oleh admin untuk } \\
\text { memperbarui data pinjaman } \\
\text { anggota }\end{array}$ \\
\hline 10 & $\begin{array}{l}\text { Upload Bukti } \\
\text { Pembayaran }\end{array}$ & $\begin{array}{l}\text { Menu yang hanya bisa di } \\
\text { akses oleh anggota untuk } \\
\text { upload bukti pembayaran }\end{array}$ \\
\hline 11 & $\begin{array}{l}\text { Pengajuan } \\
\text { Pinjaman }\end{array}$ & $\begin{array}{l}\text { Menu yang hanya bisa di } \\
\text { akses oleh anggota untuk } \\
\text { mengajukan pinjaman }\end{array}$ \\
\hline 12 & Lihat Status & $\begin{array}{l}\text { Menu yang bisa diakses oleh } \\
\text { anggota untuk melihat status } \\
\text { anggota }\end{array}$ \\
\hline 13 & Laporan & $\begin{array}{l}\text { Menu yang hanya bisa } \\
\text { diakses oleh admin untuk } \\
\text { memperbarui siapa saja yang } \\
\text { sudah melakukan transaksi } \\
\text { dan diterima oleh ketua }\end{array}$ \\
\hline 14 & Logout & $\begin{array}{l}\text { Menu untuk keluar dari } \\
\text { sistem }\end{array}$ \\
\hline
\end{tabular}

2) Activity Diagram

Activity diagram menggambarkan berbagai alur aktivitas dalam sistem yang sedang dirancang, bagaimana masing-masing alur berawal, keputusan yang mungkin terjadi dan bagaimana mereka berakhir. Activity diagram juga dapat menggambarkan proses paralel yang mungkin terjadi pada beberapa eksekusi.

Berikut ini pemodelan Activity Diagram sistem aplikasi simpan pinjam pada Koperasi Karyawan 71 PT. Nikomas Gemilang berbasis android :

a) Prosedur Activity Diagram Pendaftaran

(1) Anggota membuka aplikasi koperasi 71.

(2) Pilih daftar baru lalu pengguna mengisi form pendaftaran

(3) Klik daftar, lalu admin akan memvalidasi data pendafatar

(4) Apabila data lengkap username dan password akan dikirm melalui email apabila data kurang lengkap pendaftar memperbaiki data yang kurang lengkap 
(5) Selesai, Login.

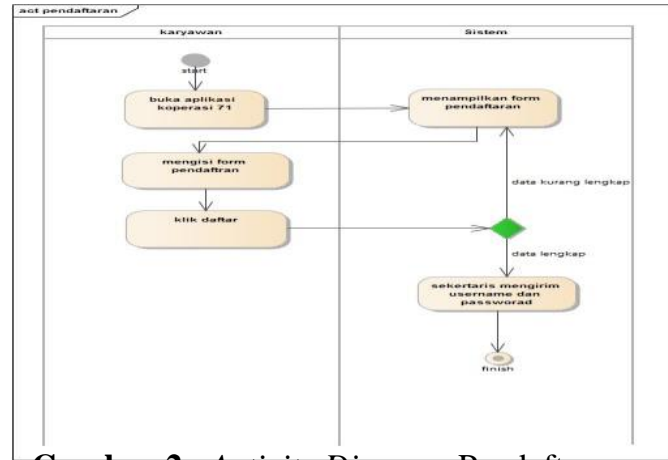

Gambar 2. Activity Diagram Pendaftaran

b) Prosedur Activity Diagram Login

(1) Anggota atau Admin membuka aplikasi koperasi 71.

(2) Sistem akan memapilakan form username dan password.

(3) Users mengisi form username dan password.

(4) Apabila username dan password benar sistem akan menampilakan menu-menu.

(5) Apabila username dan password salah login fail.

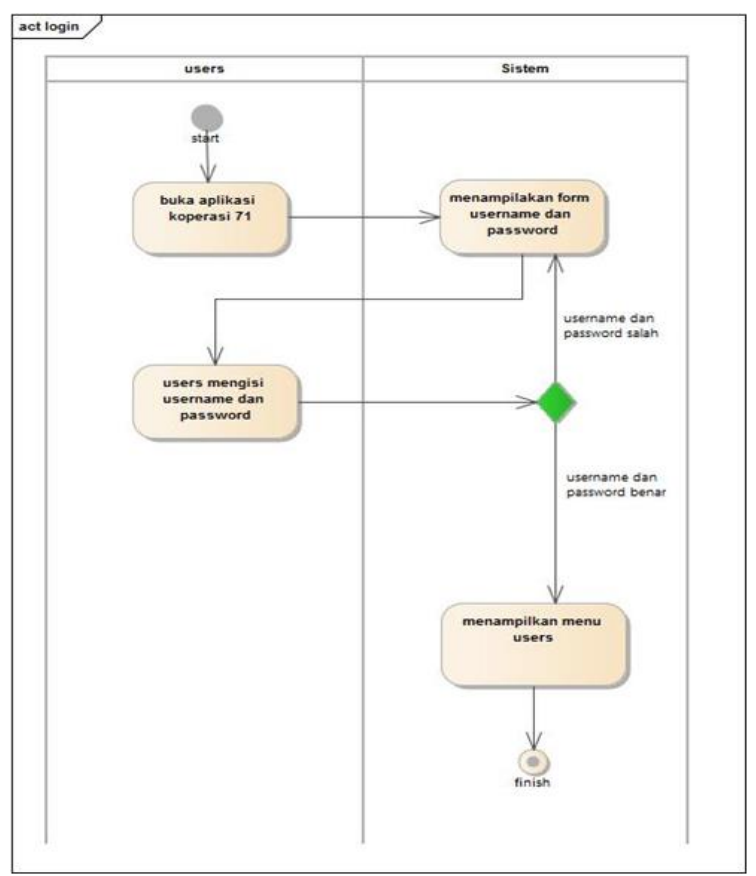

Gambar 3. Activity Diagram Login

c) Prosedur Activity Diagram Mengolah Daftar Anggota

(1) Setelah Admin login sistem akan menampilkan menu-menu salah satunya menu daftar anggota.

(2) Admin akan mengakses daftar anggota.

(3) Apabila ada yang di perbarui klik edit atau fitur plus(+) untuk menambah anggota.

(4) Apabila ada yang dihapus klik delete

(5) Simpan

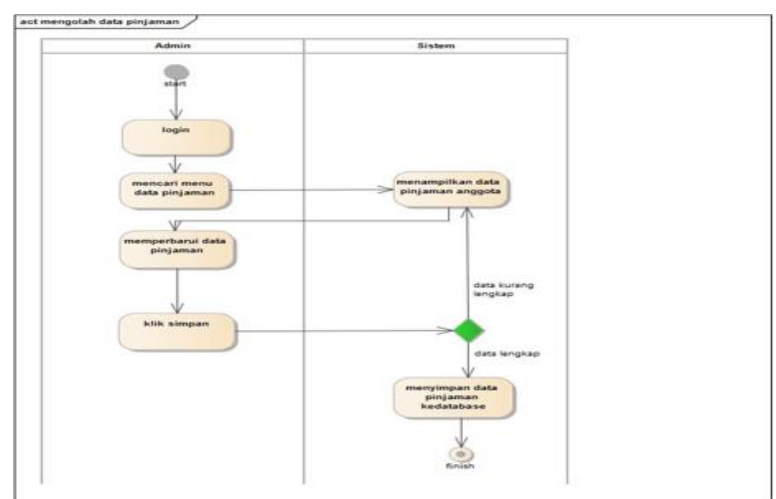

Gambar 4. Activity Diagram Mengolah Data Pinjaman

d) Activity Diagram Upload Bukti Pembayaran

(1) Anggota login mencari menu upload bukti pembayaran setelah di klik sistem akan menampilakan upload gamabar.

(2) Anggota mencari gambar yang akan upload di galeri hp meraka.

(3) Apabila sudah klik gambar.

(4) Upload.

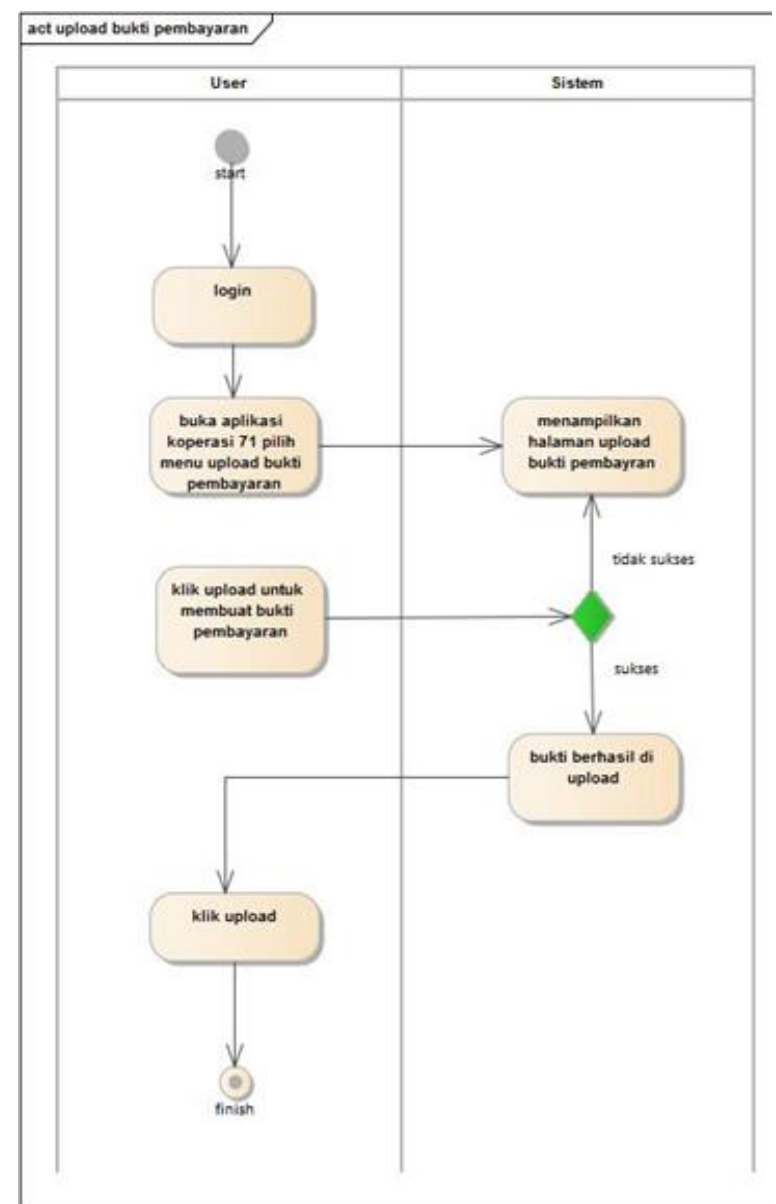

Gambar 5. Activity Diagram Upload Bukti Pembayaran 
e) Activity Diagram Pengajuan Pinjaman

(1) Anggota login mencari menu pengajuan pinjaman lalu klik menu pengajuan pinjaman.

(2) Akan menampilkan form pengajuan.

(3) Anggota mengisi form pengajuan, klik ajuakan.

(4) Admin akan mengecek data peminjam apabila lengkapa akan dihubungi lewat email.

(5) Selesai.

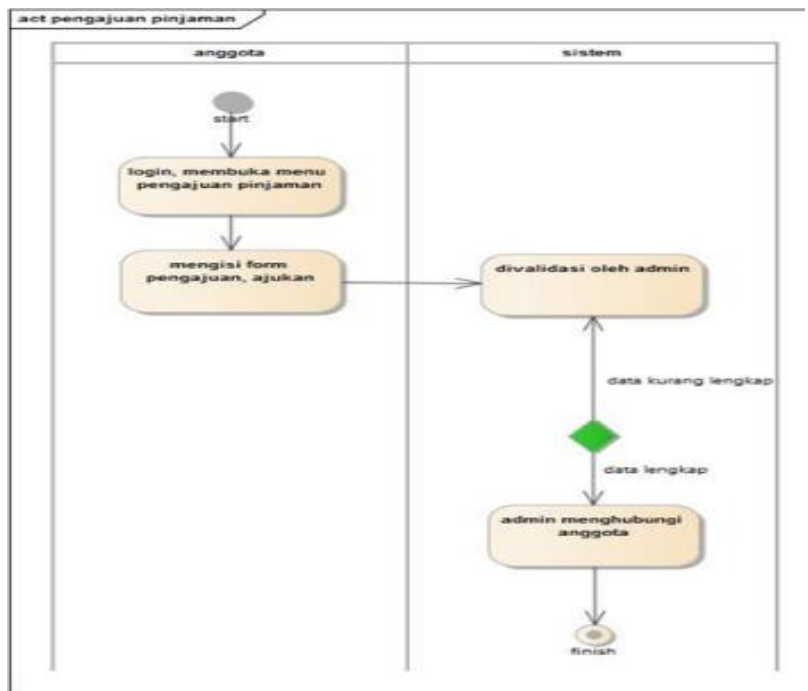

Gambar 6. Activity Diagram Pengajuan Pinjaman

f) Activity Diagram Lihat Status

(1) Anggota login mencari menu lihat status lalu klik.

(2) Akan menampilkan menu.

(3) Anggota melihat status aman atau tidak, selesai.

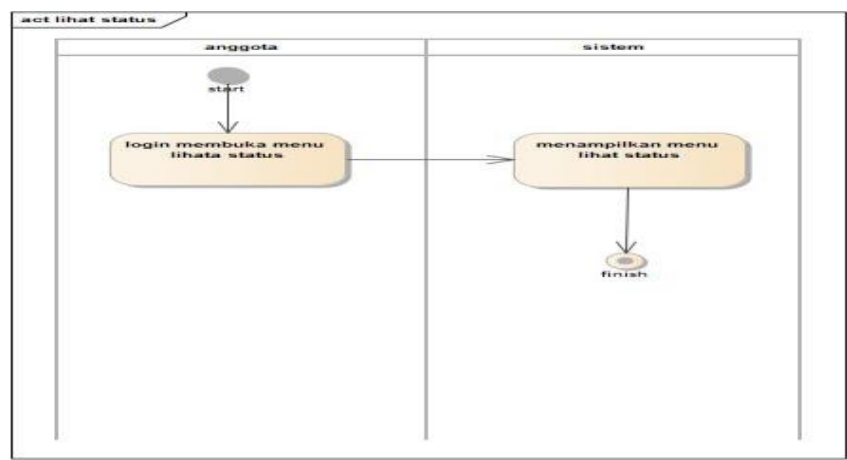

Gambar 7 Activity Diagram Lihat Status

g Activity Diagram Laporan

(1) Pengurus login mencari menu laporan lalu klik.

(2) Menu laporan akan menampilakan daftar anggota yang meminjam dan pembayaran simpanan.

(3) Pengurus akan mengecek semua simpanan dan pinjaman anggota
(4) Apabila ada anggota yang belum melakukan transaksi status tidak aman apabila sudah melakukan semua transaksi status aman.

(5) Selesai.

\section{Class Diagram (Diagram Kelas)}

Merupakan bagian terpenting dari UML (unified modeling language). UML adalah pemodelan dalam bentuk implementasi sistem yang dibutuhkan ketika hendak membuat suatu aplikasi.

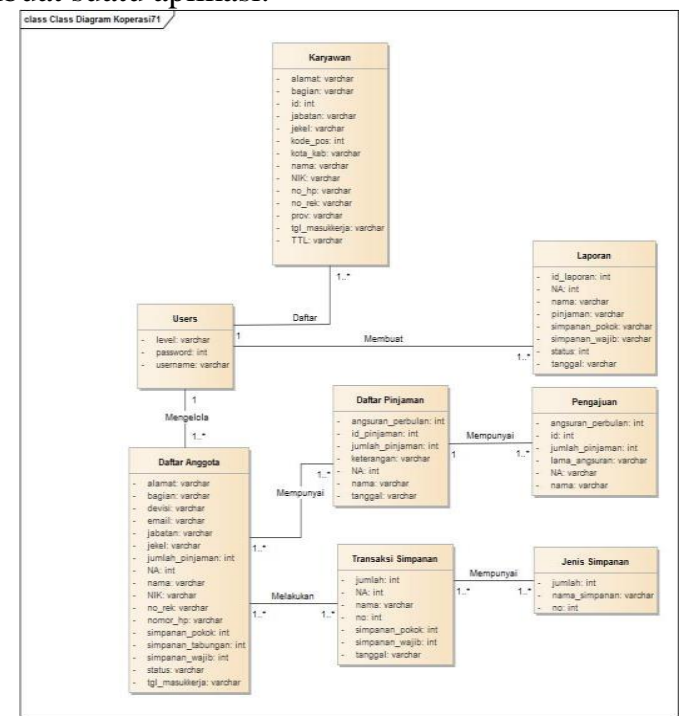

Gambar 8. Class Diagram

Untuk tahap pengujian, peneliti menggunakan metode blackbox testing. Metode blackbox testing merupakan metode pengujian program yang mengutamakan terhadap kebutuhan fungsi dari suatu program. Tujuannya adalah untuk menemukan kesalahan fungsi dari program yang diujikan. Dilakukan hanya untuk mengamati hasil dari eksekusi melalui data uji dan juga memeriksa fungsional dari software dan fungsionalitasnya tanpa mengetahui yang terjadi dalam proses detail, melainkan hanya mengetahui input dan output. Dalam pengoperasian aplikasi android koperasi simpan pinjam harus mengikuti prosdur sebagai berikut:

1. Hidupkan Laptop/komputer sesuai dengan standar yang telah ditentukan.

2. Buka project koperasi71 yang telah disimpan dengan vscode.

3. Buka Xampp pilih start pada apche dan mysql.

4. Hubungkan laptop dengan smartphone yang telah menjadi mode pengembang

5. Hubungkan ke wifi smartphone.

6. Running pada vscode.

7. Login sesuai status level dan daftar baru apabila ingin menjadi anggota. 


\section{KESIMPULAN}

Penelitian ini dilakukan untuk menganalisis sistem simpan pinjam yang terdapat pada Koperasi Karyawan '71' PT. Nikomas Gemilang. Kemudian dari hasil analisis tersebut, dirancang suatu sistem simpan pinjam baru yang berbasis teknologi informasi yang bertujuan untuk meningkatkan efisiensi waktu dan efektifitas kerja karyawan. Dari hasil uraian tersebut diatas dapat ditarik simpulan sebagai berikut:

1. Dengan aplikasi ini sistem informasi simpan pinjam pada Koperasi Karyawan '71' PT. Nikomas Gemilang yang selama ini sering kali terjadi kerangkapan data, akan lebih mudah untuk menyimpan data.

2. Dan dengan aplikasi ini proses pelayanan transaksi baik simpanan maupun pinjaman akan lebih mudah sehingga tidak menimbulkan ketidaknyamanan bagi pegawai koperasi dan anggota.

3. Aplikasi ini akan mudah diakses sehingga anggota yang akan bertransaksi tidak perlu mengunjungi kantor koperasi71.

\section{SARAN}

Penelitian ini dapat dijadikan bahan masukan bagi Koperasi Karyawan '71' PT. Nikomas Gemilang agar lebih memperhatikan kelemahan-kelemahan yang terdapat dalam sistem simpan pinjamnya sehingga diharapkan dapat mengurangi resiko-resiko yang mungkin terjadi. Sistem yang dirancang dengan menggunakan basis teknologi informasi diharapkan dapat memberikan gambaran agar keefektifan kerja dalam koperasi dapat terwujud. Di samping itu, karena struktur organisasi Koperasi Karyawan '71' PT. Nikomas Gemilang masih kurang dioptimalkan, diharapkan dari rancangan sistem ini ada pembagian tugas yang jelas dalam pelaksanaan simpan pinjamnya agar bagian- bagian yang bertugas dapat melakukan fungsinya dengan baik. Untuk itu penulis menyarankan beberapa hal :

1. Sistem basis data yang dibangun harus terintegrasi dengan basis data karyawan pada perusahan PT. Nikomas Gemilang dengan tujuan memudahkan proses pengolahan data.

2. Pelatihan bagi petugas koperasi untuk sistem aplikasi yang akan dikembangkan.

3. Perlunya sistem informasi yang baik melalui penggunaan salah satu aplikasi yang sesuai dengan kebutuhan.

\section{REFERENSI}

[1]A. Nurhanafi, "Sistem Informasi Simpan Pinjam Pada Koperasi Sari Mulyo Kecamatan Ngadirojo,” Indones. J. Netw. Secur., vol. 3, no. 3, pp. 41-49, 2014.

[2] N. Purwandari, S. Informasi, and I. Teknologi, "Aplikasi Simpan Pinjam Pada Koperasi Keluarga Karyawan Kalbis Sejahtera Berbasis Website," J. Ilm. Komputasi, vol. 18, no. 3, 2019, doi: 10.32409/jikstik.18.3.2651.

[3] Lesta Susia Febriyanti, Sistem Akuntansi Piutang Pada Koperasi Pegawai Republik Indonesia Karya Mukti Kabupaten Pati. 2013.

[4] Yuli Syafitri, "Analisa Dan Perancangan Berbasis Uml Pada Sistem Informasi Simpan Pinjam Koperasi Swamitra Bandar Lampung," Manaj. Inform., pp. 22 31, 2012.

[5] A. Najmi and M. Nadjib, "Simpan Pinjam Berbasis Website," vol. 5, no. 1, pp. 9-17, 2020.

[6] G. Saputri and E. S. Eriana, "Implementasi Metode Waterfall Pada Perancangan Sistem Informasi Koperasi Simpan Pinjam Berbasis Web Dan Android (Studi Kasus Pt. Peb)," J. Tek. Inform., vol. 13, no. 2, pp. 133146, 2021, doi: 10.15408/jti.v13i2.17537.

[7] N. Hidayanti, W. Widyawati, R. Fatullah, and B. Budiono, "Rancang bangun aplikasi monitoring kegiatan kuliah kerja mahasiswa berbasis android di Universitas Banten Jaya," Tek. J. Sains dan Teknol., vol. 16, no. 2, p. 267, 2020, doi: 10.36055/tjst.v16i2.8680.

[8] I. G. T. Isa and G. P. Hartawan, "Perancangan Aplikasi Koperasi Simpan Pinjam Berbasis Web (Studi," J. Ilm. Ilmu Ekon., vol. 5, no. 10, pp. 139-151, 2017.

[9] T. I. Solihati, I. Nuraida, and N. Hidayanti, "Pemanfaatan Kardus Menjadi Tempat Sampah Pintar Berbasis Arduino UNO R3," ABDIMAS J. Pengabdi. Masy., vol. 3, no. 2, pp. 342-350, 2020, doi: 10.35568/abdimas.v3i2.962

[10]D. Syahrul Suci Romadhon1, "Perancangan Website Sistem Informasi Simpan Pinjam Menggunakan Framework Codeiginter Pada Koperasi Bumi Sejahtera Jakarta," J. Inf. Syst. Informatics Comput., vol. 3, no. 1, pp. 21-28, 2019. 